\title{
Memory performance in Brazilian school-age children
}

\author{
Luciana Brooking ${ }^{1,2}$, Emmy Uehara ${ }^{1}$, Helenice Charchat-Fichman ${ }^{1}$, J. Landeira-Fernandez ${ }^{1,3}$ \\ 1 - Pontifícia Universidade Católica do Rio de Janeiro, Rio de Janeiro, RJ, Brazil \\ 2 - Universidade Estadual do Rio de Janeiro - Rio de Janeiro, RJ, Brazil \\ 3 - Universidade Estácio de Sá, Rio de Janeiro, RJ, Brazil
}

\begin{abstract}
The purpose of the present study was to investigate different memory systems among children of different school ages. Ninety children who attend schools within the Rio de Janeiro municipality school system, ages 6 to 10 years, were studied. The study excluded children with learning disabilities. All children underwent a neuropsychological evaluation. A two-way analysis of variance revealed significant gender differences in the free delay episodic memory. Age differences were found for the free delay episodic memory and recognition on the Rey Auditory Verbal Learning Test (RAVLT) as well as the recall of the Rey Figure. Semantic memory correlated with Semantic Verbal Fluency. Working Memory as measured by Digit Span subtest of the WISC correlated with the first list learning of the RAVLT. Overall, study results indicated a lower performance among 6-year-old children and gender differences in children 8 and 10 years of age. Data are consistent with the literature and show a distinction in the evolution of different memory systems throughout life.
\end{abstract}

Keywords: neuropsychology; childhood; memory development.

Received 11 May 2012; received in revised form 26 September 2012; accepted 01 October 2012. Available online 28 December 2012.

\section{Introduction}

Memory is a neurocognitive construct that can be classified into different systems and processes. Each system develops and is established during a particular period of life. The first months of life already show signs of memory that progressively improve with age (Bauer, 2006). Therefore, it appears that that memory consists of different types and stages, each with their own specific mode of operation but all cooperating in memory processes. The first process is coding and learning new information. The second process is retention and information consolidation including sensory and short- and long-term memory (Cowan, 1988; Baddeley, 2002, 2009). The third process is retrieval and information recall.

Human memory can also be classified into two main storage modes: long-term and short-term memory. Long-term memory (LTM) consists of two systems: implicit memory (i.e., unconscious) and explicit memory (i.e., conscious). Implicit memory is characterized by

J. Landeira-Fernandez, Emmy Uehara and Helenice CharchatFichman, Núcleo de, Neuropsicologia Clínica e Experimental, Departamento de Psicologia, Pontifícia Universidade Católica do Rio de Janeiro, PUC-Rio - Rio de Janeiro, RJ, Brazil. Luciana Brooking, Instituto de Psicologia, Programa de Pós-graduação em Psicologia, Universidade do Estado do Rio de Janeiro, UERJRio de Janeiro, RJ, Brazil. Correspondenceregarding this article should be directed to: J. Landeira-Fernandez, Núcleo de Neuropsicologia Clínica e Experimental, Departamento de Psicologia, Pontifícia Universidade Católica do Rio de Janeiro, PUC-Rio, Rua Marquês de São Vicente, 225, Rio de Janeiro, RJ, 22453-900, Brazil. Tel: +55-21-3527-2075. Fax: +55-2135271187. E-mail: landeira@puc-rio.br habits, skills, and automatic processes (Squire, 2009). Explicit memory is divided into the episodic memory and the semantic memory (Squire, 2009; Fivush, 2011). Short-term or working memory is an active process of storing and retaining information for a limited period of time. This type of memory is divided into systems for different types of input stimuli: phonological loop, visuospatial sketchpad, central executive, and episodic buffer (Baddeley, 2002, 2009).

Throughout development, memory undergoes several modifications (Carneiro, 2007). During the first months of life there is a rudimentary recognition memory (Barr, Dowden, \& Hayne, 1996; Bauer, 2006). Before 1 year of age, for example, a child can recall new events after an interval of time (Mandler \& McDonough, 1995). At the end of the first year of life, long-term memory may begin to develop (Carver, Bauer, \& Nelson, 2000). Following the development of language (Nelson \& Fivush, 2004) and mental planning (Greenbaum \& Graf, 1989), preschool children elaborate explicit memories.

Greenbaum \& Graf (1989) suggested that implicit memory becomes functional before explicit memory. The latter requires the translation of instructions, planning evaluation to store information, remembering the plan, and accessing memory according to the plan. Improvements in each of these steps help in the evocation and elaboration of more robust strategies, thus making the memory more efficient and achieving better performance.

The establishment of more robust strategies is linked to the central executive, one of the components of working memory, which has a fundamental role in the development of memory. Although it is an 
immature skill in younger children, several authors have documented how much it can be elicited (Anderson and Lajoie, 1996; Brocki and Bohlin, 2004). Studies on switch and clusters in verbal fluency tasks show clearly how this ability develops differently throughout childhood (Sauzéon, Raboutet, n' Lestage, Kaoua Street and Claverie, 2004). The Anderson (2001) review presents studies showing the trajectory of development of that cognitive function.

Some studies have found differences in working memory. Conlin, Gathercole, \& Adams (2005), for example, found that 9-year-old children performed better than 7-year-old children and were faster, but these age groups did not differ in storage capacity (i.e., span) in a more complex task. When evaluating visual working memory, one test that can be used as a strategy measure that influences delayed recall is the Rey Complex Figure Test, although not a classic measure to evaluate this function. Older children tend to perform better than younger children both in copying and evocation because of better organizational and developmental strategies (Frisk, Jakobson, Knight, \& Robertson, 2005). This improvement occurs with age. Seven- and 8-year-old children show little organizational strategies in copying (Anderson, Anderson, \& Garth, 2001). Improvement occurs with age when using a step-by-step strategy, even in 6-year-old children (Frisk et al., 2005). Thus, better performance is observed on the immediate memory test of the Rey Complex Figure Test when copying is structured and well-planned (Oliveira, Rigoni, Andretta, \& Moraes, 2004).

Distinguishing memory processes in school-age children is possible. With regard to episodic memory, for example, the effects of age can be observed between different age groups, mainly on the Rey Auditory Verbal Learning Test (RAVLT). From 8 to 17 years of age, the measures are not linear. Changes at 8 to 10 years of age are greater than at 11 to 17 years of age (Vakil, Blachstein, \& Sheinman, 1998). In a Brazilian study, 8 -year-old children were not observably different from 7-, 9-, and 10-year-old children (Oliveira \& CharchatFichman, 2008). Evidence shows age-related differences in memory development, with older children recalling more words than younger children (Vakil et al., 1998; Farrar \& Goodman, 1992; Ceci \& Howe, 1978).

In a task in which the subject must learn a list of words, a strong positive correlation is found between recall and recognition. Recognition is an easier task than recall because more words tend to be recognized than free-recalled (Oliveira \& Charchat-Fichman, 2008). Studies have found differences in the abilities of boys and girls, suggesting that girls have better verbal learning (Kramer, Delis, Kaplan, O’Donnell, \& Prifitera, 1997). At 10 years of age, girls perform better than boys in recognition memory tasks, but boys score slightly better than girls in visual memory when the figure is male, indicating gender identification (McGivern, Huston, Byrd, King, Siegle, \& Reilly, 1997).

Concerning gender, some studies have found differences. Girls generally perform better on verbal tasks, and boys perform better on spatial tasks (Lowe, Mayfield, \& Reynolds, 2003). On the RAVLT, girls exhibit better performance than boys (Anderson \& Lajoie, 1996; Vakil et al., 1998; Vakil, Greenstein, \& Blachstein, 2010).

With regard to semantic memory, some studies evidenced age and gender difference across the lifespan. Eight-, 12-, and 21-year-old subjects exhibited an increase in the free recall of words of animals and furniture with advancing age but no increase in the number of categories (Kail \& Nippold, 1984). Sauzéon et al. (2004) studied 7- to 16-year-old children and their evocation of fruit and grocery items. An improvement with age was found mainly at 9 to 10 years of age compared with 7 to 8 years of age. Studies show that the improvement in semantic memory among children correlates with the improvement in semantic verbal fluency task (Nieto, Galtier, Barroso, \& Espinosa, 2008), with girls exhibiting better semantic memory performance than boys (Kramer et al., 1997).

Older children exhibit better performance on memory tasks. Anderson and Lajoie (1996) studied 7and 8 -year-old children and found that their performance on several memory tests was significantly poorer than 9to 13-year-old children. Similar results were found on the RAVLT, Rey Complex Figure Test, and Digit Span subtest.

Despite a large international literature (Gathercole, 1998; Alloway, Gathercole, \& Pickering, 2006), Brazilian studies have found memory relationships in the context of reading and writing. Nine- to 11-yearold children who have poorer performance on memory tasks also have more learning difficulties with regard to writing (Souza \& Sisto, 2001). Using the Digit Span subtest of the Wechsler Intelligence Scale for Children (WISC) and Brown-Peterson Task, version 11 for children, working memory performance gradually improved in 103 children aged 6 to 11 years (Vaz, Cordeiro, Macedo, \& Lukasova, 2010). The best performance on working memory tasks was found concomitantly with writing and phonological awareness in 6- and 7-year-old children (Gindri, Keske-Smith, \& Mota, 2007). Phonological working memory improves with age when comparing children, adults, and elderly subjects (Capovilla, Gütschow, \& Capovilla, 2004; Grivol, \& Hage, 2010). In a study by Pagliuso and Pasian (2007), 9- and 10-year-old children performed below the national average in visual memory on the Rey Complex Figure Test.

Thus, the data reported above indicate the importance of investigating memory function and behavior with regard to school performance because of the development of strategies and metamemory, more elaborate concept formation, and increased processing speed. Access to long-term memory, working memory, and vocabulary extension are also relevant when studying memory development.

However, few studies have verified the development of memory as a whole with all systems or at least 
episodic, semantic, and working memory. Generally, previous studies have explored only one memory system. Furthermore, knowledge of how explicit memory systems operate and interact in normal school-age children may contribute to the development of learning programs. Normative data could also be used as a reference for comparisons with children with learning or memory disabilities. Therefore, the purpose of the present study was to characterize the performance of school-age children with regard to working, episodic, and semantic explicit memory systems.

\section{Materials and Methods}

\section{Sample}

The sample consisted of 90 students ( 44 boys and 46 girls) aged 6 to 10 years. These children were students from private schools in Rio de Janeiro from the $1^{\text {st }}$ to the $5^{\text {th }}$ grade (Tables 1 and 2). Their socioeconomic status was classified as A or B, based on the criteria of the Brazilian Institute of Geography and Statistics (IBGE, 1999). Exclusion criteria were learning difficulties and disorders according to a report by the school director and low-average performance on the Academic Performance Test (Stein, 1994).

Family members of the children signed consent forms that contained pertinent study information. The study design was submitted to and approved by the ethics committee on research of the Department of Psychology, Catholic University of Rio de Janeiro (PUC-Rio).

Table 1. Sociodemographic data

\begin{tabular}{lcccccc}
\hline Age (years) & $\mathbf{6}$ & $\mathbf{7}$ & $\mathbf{8}$ & $\mathbf{9}$ & $\mathbf{1 0}$ & Frequency (\%) \\
\hline$n$ & 16 & 18 & 20 & 16 & 20 & $90(100)$ \\
Gender & & & & & & \\
Male & 9 & 10 & 9 & 7 & 9 & $44(48.9)$ \\
Female & 7 & 8 & 11 & 9 & 11 & $46(51.1)$ \\
$\begin{array}{l}\text { Socioeconomic } \\
\text { level }\end{array}$ & & & & & & \\
Class A & 12 & 7 & 7 & 5 & 10 & $41(45.6)$ \\
Class B & 4 & 11 & 13 & 11 & 10 & $49(54.4)$ \\
$\begin{array}{l}\text { Academic } \\
\text { Performance }\end{array}$ & & & & & & \\
Test & & & & & & \\
Writing & & & & & & \\
Above average & 11 & 17 & 10 & 10 & 11 & $59(65.6)$ \\
Average & 5 & 1 & 10 & 6 & 9 & $31(34.4)$ \\
Reading & & & & & & \\
Above average & 9 & 11 & 5 & 8 & 13 & $46(51.1)$ \\
Average & 7 & 7 & 15 & 8 & 7 & $44.9)$ \\
\hline
\end{tabular}

Table 2. Clinical data

\begin{tabular}{lc}
\hline Clinical data & Frequency (\%) \\
\hline$n$ & $90(100)$ \\
P-Chips & \\
No symptoms & $69(76.7)$ \\
Symptoms & $21(23.3)$ \\
Hypomania & $1(1.1)$ \\
Hypomania/Psychosis & $1(1.1)$ \\
Psychosis & $1(1.1)$ \\
Attention Deficit Hyperactivity Disorder & $7(7.8)$ \\
ADHD duration / Encopresis & $1(1.1)$ \\
Oppositional Defiant Disorder & $7(7.8)$ \\
ODD/ADHD & $3(3.3)$ \\
MASC & \\
No symptoms & $78(86.7)$ \\
Symptoms & $12(13.3)$ \\
CDI & \\
No symptoms & $90(100)$ \\
Symptoms & $0(0)$ \\
\hline
\end{tabular}

\section{Instruments}

A battery of eight tasks was used to assess different types of memory, and three behavioral scales were used for exclusion criteria. Table 3 presents these tests.

Parent and Children Interview for Psychiatric Syndromes (P-Chips). This is a structured interview with children and adolescents aged 6 to 18 years and their parents. The interview is based on the DSMIV. Results are presented concisely and with easy interpretation. In the present study only the parental interview is applied. The questions are objective and straightforward, allowing the understanding and cooperation of the respondents. The administration time is 20 min (Weller, Weller, Rooney, \& Fristad, 1999).

Multidimensional Anxiety Scale for Children. This scale was developed by March, Parker, Sullivan, Stallings and Conners (1997) and assesses anxiety symptoms in children and adolescents aged 8 to 19 years. Average application time was $15 \mathrm{~min}$ in which the child rated, according to his/her perception, 39 items on a four-point Likert-type scale. Four main areas are subdivided into other factors: (1) physical symptoms, somatization, and muscle strains, (2) social anxiety, humiliation, and rejection, (3) avoidance behavior to deal with anxiety and perfectionism, and 4) anxiety during separation.

Children's Depression Inventory (CDI). This instrument was developed by Kovacs (1983) and adapted from the Beck Depression Inventory (BDI; Beck, Ward, 
Mendelson, Mock, \& Erbaugh, 1961). The aim of this test is to identify depressive symptoms in 7- to 17-yearold subjects. Average application time was $10 \mathrm{~min}$ in which the children responded to 27 items with which they most identified, based on their thoughts and feelings in the last 2 weeks, among three options. This instrument assesses five factors: (1) negative mood, (2) interpersonal problems, (3) inefficiency, (4) anhedonia, and (5) negative self-esteem (Kovacs, 1992).

School Performance Test. This test evaluates fundamental capacities for school performance. The instrument has three subtests: writing (in which the child writes his name and single words in the form of dictation), arithmetic (not used), and reading (read and recognize isolated words within a context). For school performance, the first and third subtests were used (Stein, 1994).

Wechsler Intelligence Scale for Children (WISCIII). This battery assesses intellectual ability intelligence and global cognitive processes. The instrument consists of verbal and executive subtests. In the present study we used the subtests that provide information about memory function. In the Information subtest, the child is asked to respond to social and cultural issues. In the Digit Span forward and backward subtest, the child repeats an increasing sequence of numbers given by the examiner in forward or backward order. The score was calculated as the sum of forward and backward subtests as recommended in WISC-III. In the Vocabulary subtest, the child is asked to explain word meanings (Wechsler, 2006).

Rey Auditory Verbal Learning Test. This test evaluates verbal anterograde episodic memory, learning, and executive function. In the present study, we used the version of Oliveira and Charchat-Fichman (2008) that uses two lists (A and B), each with 12 nouns. List A is read four times by the evaluator. At the end of each reading the subject must recall as many words as possible (A1-A4). Afterward, an interference list (List B) is read by the evaluator, followed by recall. List A is again recalled, this time without presenting it (A5). Twenty minutes later, the subject is asked to free-recall List A (A6) and to recognize List A and B (12 words from List A, 12 words from List $\mathrm{B}$, and 30 distracting words). Each word must be followed by the child saying whether the word was from List A, List B, or neither. The following items are calculated: total number of words recalled (A1-A4), sum of items from four attempts (total learning score), difference between trials 4 and 1 (learning score), difference between number of hits and false positives in the recognition test, proactive interference (B1/A1), retroactive interference (A5/ A4), and forgetfulness (A6/A5) (Diniz, Cruz, Torres, \& Cosenza, 2000).

Semantic Fluency Test (animals, clothes, and fruit). This test assesses semantic memory, attention, language, and executive function. In the semantic category, the child must name, as quickly as possible, many different animals as possible in $60 \mathrm{~s}$. This instruction is repeated with categories of clothes and fruits (Sauzéon et al., 2004).
Table 3. Memory tests

\begin{tabular}{lll}
\hline Episodic memory & Semantic memory & Working memory \\
\hline $\begin{array}{l}\text { Rey Auditory Verbal } \\
\begin{array}{l}\text { Learning Test Late } \\
\text { Recall }\end{array}\end{array}$ & $\begin{array}{l}\text { Information subtest } \\
\text { of WISC }\end{array}$ & $\begin{array}{l}\text { Digit subtest of } \\
\text { WISC }\end{array}$ \\
Rey Figure Recall & $\begin{array}{l}\text { Vocabulary subtest } \\
\text { of WISC }\end{array}$ & A1 list \\
Rec A & Verbal fluency & Copy of Rey figure \\
\hline
\end{tabular}

Rey-Osterrieth Complex Figure Test. This test assesses visuospatial perception/construction (planning, organizing, problem-solving strategies, visual function, and motor function), visual episodic memory and central executive (component of working memory) (Strauss, Sherman, \& Spreen, 2006). The child must copy a figure onto a blank sheet of paper. After $5 \mathrm{~min}$, the child is requested to draw the figure again, this time without the presence of the original figure (Rey, 1998/1999).

\section{Procedures}

All subjects underwent the same clinical protocol and were tested individually in rooms within the school, the Laboratory of Clinical Neurosciences (LACLIN), or a private practice room. The study consisted of three sessions: one with parents and two with children. A semistructured interview was conducted with the parents concerning their children's development, and they completed a structured questionnaire based on the diagnostic criteria of the Diagnostic and Statistical Manual of Mental Disorders, 4th edition (DSM-IV; American Psychiatric Association, 1994) to report behavioral and cognitive deficits. Assessment of the children occurred in two sessions, each lasting $40 \mathrm{~min}$.

In the first session the children were subjected to three subtests of the WISC-III (Digit Span, Vocabulary, and Block Design) and the School Performance Test (Reading and Writing). In the second session, the children were subjected to the Rey-Osterrieth Complex Figure Test, Semantic Verbal Fluency Test, RAVLT, WISC-III Vocabulary subtest, and two behavioral/ emotional and cognitive scales (i.e., Child Depression Inventory $[\mathrm{CDI}]$ and Multidimensional Anxiety Scale for Children [MASC]).

The interview and assessment were performed by neuropsychologists and trainees previously trained in test application and evaluation. The order of the application of the tests was standardized and flexible according to the child's performance or external factors. Parents received the test results and referrals when necessary. The school also received performance reports for all of their students.

\section{Statistical analysis}

A two-way analysis of variance (ANOVA) was used to evaluate the effects of age and gender on the memory tests. Differences between age groups were followed 
by the Least Significance Difference (LSD) post hoc test. Gender differences were analyzed using Student $t$-test for independent samples; $p=.05$ was considered statistically significant. All analyses were performed using SPSS 16.0 software (SPSS, Chicago, IL, USA).

\section{Results}

Results indicated differences between age and gender (Table 4). ANOVA revealed a two-way interaction only in the copying of the Rey figure $(F$ $=2.836, p \leq .05)$. Differences between genders were observed only for 7 and 8 years of age. Seven-year-old boys performed better than girls $(p=0.05)$. At 8 years of age, the difference is reversed, showing that girls performed better than boys $(p<0.01)$.

Gender differences were found on the A6 list of the RAVLT (i.e., delayed recall), which evaluates episodic memory, $(F=4.778, p \leq .05)$ with girls performing better than boys. Significant age differences were found $(F=6.654, p \leq .01)$. The LSD post hoc test revealed significant differences between 6- and 7-year-olds ( $p \leq$ $.01), 8$-year-olds $(p \leq .01)$, 9-year-olds $(p \leq .01)$, and 10 -year-olds $(p \leq .01)$ and between 7 -year-olds and 10 -year-olds $(p \leq .01)$.

Recognition of the RAVLT list revealed significant age differences $(F=2.438, p \leq .05)$. The LSD post hoc test revealed significant differences between 6-year-olds and 8-year-olds $(p \leq .05)$ and between 6 -year-olds and 10-year-olds $(p \leq .05)$.

Recall of the Rey figure showed significant age differences $(F=9.951, p \leq .01)$. The LSD post hoc test revealed a significant difference between 6-year-olds and 7-year-olds $(p=.01), 8$-year-olds $(p=.01), 9$-yearolds $(p \leq .01)$, and 10-year-olds $(p \leq 0.01)$.

With regard to semantic memory, a significant difference in Semantic Verbal Fluency was found ( $F$ $=10.457, p \leq .01)$. The LSD post hoc test revealed a significant difference between 6-year-olds and 7-year-olds ( $p \leq .05), 8$ years-olds ( $p \leq .01)$, 9-year-olds $(p \leq .01)$, and 10 -year-olds $(p \leq .01)$, between 7-year-olds and 9-year-olds $(p \leq .01)$ and 10-year-olds $(p \leq .01)$, and between 8-yearolds and 9-year-olds $(p \leq .01)$ and 10-year-olds $(p \leq .05)$.

Significant age differences were found on the Vocabulary subtest of the WISC $(F=18.205, p \leq .01)$. The LSD post hoc test revealed significant differences between 6-year-olds and 8-year-olds $(p \leq .01)$, 9-yearolds $(p \leq .01)$, and 10-year-olds $(p \leq .01)$, between 7 -year-olds and 8-year-olds $(p \leq .01), 9$-year-olds $(p \leq$ $.01)$, and 10-year-olds $(p \leq .01)$, and between 8-yearolds and 9-year-olds $(p \leq .05)$ and 10-year-olds $(p \leq .01)$.

Significant age differences were found on the Information subtest of the WISC $(F=29.927, p \leq 0.01)$. The LSD post hoc test revealed significant differences between 6-year-olds and 7-year-olds $(p \leq .01), 8$-yearolds $(p \leq .01)$, 9-year-olds $(p \leq .01)$, and 10-year-olds $(p \leq .01)$, between 7-year-olds and 9-year-olds $(p \leq .01)$ and 10-year-olds ( $p \leq .01)$, and between 8 -year-olds and 9 -year-olds $(p \leq .01)$ and 10 -year-olds $(p \leq .01)$.
With regard to working memory on the A1 list of the RAVLT, two-way ANOVA revealed significant age differences $(F=3.596, p \leq .01)$. The LSD post hoc test revealed significant differences between 6-year-olds and 8 -year-olds ( $p \leq .05)$, 9-year-olds ( $p \leq .05)$, and 10-yearolds $(p \leq .01)$ and between 7-year-olds and 10-year-olds $(p \leq .01)$.

Significant age differences were found on the Digit Span subtest of the WISC $(F=5.620, p \leq .01)$. The LSD post hoc test revealed significant differences between 6 -year-olds and 8-year-olds ( $p \leq .05), 9$-year-olds $(p=$ $.01)$, and 10-year-olds $(p \leq .01)$ and between 7-year-olds and 9-year-olds $(p \leq .01)$ and 10-year-olds $(p \leq .01)$.

Significant age differences were found in copying the Rey figure $(F=13.369, p \leq .01)$. The LSD post hoc test revealed significant differences between 6-year-olds and 7-year-olds $(p \leq .01), 8$-year-olds $(p \leq .01)$, 9-yearolds $(p \leq .01)$, and 10-year-olds $(p \leq .01)$ and between 10 -year-olds and 7-year-olds $(p \leq .01)$ and 8 -year-olds $(p \leq .01)$.

\section{Discussion}

The present study examined the improvement of episodic, semantic and working memory in school-age children. The study showed developmental differences on the Rey Complex Figure Test among 10-year-old children. Performance on the delayed recall trial (A6) list of the RAVLT was poorer among 6-year-old children and was different from the 8- and 10-year-olds in recognition. Overall, these findings are consistent with the literature that reveals changes in learning and recognition during infancy (Anderson \& Lajoie, 1996, Vakil et al. 2010). An improvement in performance in memory tasks occurs with age (Dempster \& Rohwer, 1983).

A strong correlation was found on tests of semantic memory in the verbal fluency test and Information and Vocabulary subtests as described in other studies of semantic memory (Sauzéon et al., 2004, Nieto et al., 2008). These data suggest that semantic memory is related to the complexity of language and education, demonstrating a close relationship between development of episodic memory and language, thinking, and executive function.

With regard to working memory on the RAVLT (A1 list), Rey Complex Figure Test, and Digit Span subtest, differences were found after 6 years of age. Most often, 6- and 7-year-old children are grouped together, and 10 -year-olds form a separate group. Anderson and Lajoie (1996) showed that older children have better temporary storage capacity (i.e., span). These data may be associated with the development of executive function and, consequently, maturation of the prefrontal cortex, exhibiting peak maturation between 6- and 12-years of age (Capovilla et al., 2004).

Executive function refers to inhibitory control, cognitive flexibility, attention, working memory, planning, organization of ideas, and monitoring (Barkley, 2001; Levin \& Hanten, 2005, Muñoz-Céspedes \& 


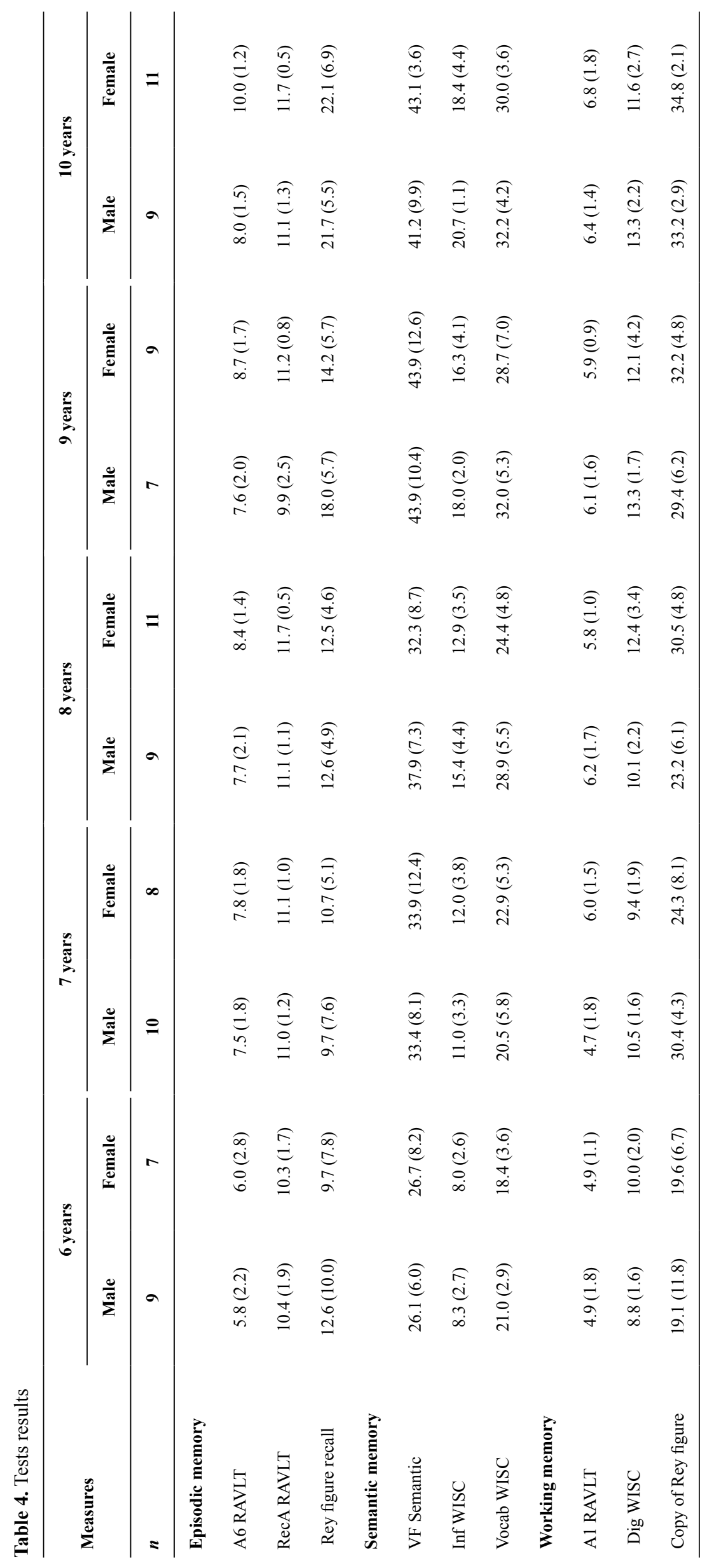


Tirapu-Ustárroz, 2004). In early childhood, executive functions are still developing, with peaks that occur in mid-childhood. This can be seen in semantic verbal fluency tasks that can distinguish age groups at 6 to 11 years of age. The verbal fluency task reveals cognitive flexibility and strategies associated with maturation of the frontal lobe. Word organization tends to be more successful with increasing age (Klenberg, Korkman, \& Nuuttila-Lahti, 2010; Nieto et al., 2008).

In a study by Flores-Mendoza, Mansur-Alves, Lele, and Bandeira (2007), 5- to 11-year-old children showed no significant difference in performance on some cognitive tasks or in psychomotor skills. Fernando, Chard, Butcher, and McKay (2003) studied 7- to 18 -year-olds and found no difference in visual memory. Thilers, MacDonald, and Herlitz (2007) also found no difference in tasks that assess semantic memory. No difference was found in working memory in 4- to 11 -year-old children, especially on verbal and visual tasks (Alloway et al., 2006).

In the present study, no gender differences were found in most of the tests, although gender differences in different memory systems have been found in other studies. For example, Thilers et al. (2007) reported that females performed better on memory tasks and had better verbal performance than males, whereas males performed better than females on visuospatial tasks. Vakil et al. (2010) observed better female performance on many verbal memory measures. Similarly, Clark et al. (2006) observed better performance in females on memory tasks, whereas males performed better on motor tasks. A gender difference was found only in the A6 list in which 10-year-old girls performed better than boys. Other studies have found better performance in girls on RAVLT (Anderson \& Lajoie, 1996; Kramer et al., 1997; Clark et al., 2006).

The WISC-III is an intelligence test associated with other constructs such as memory (Simões, 2002). In the present study we found a gender difference only in vocabulary, reflecting semantic memory in which boys performed better than girls. A similar result was found by Kramer et al. (1997).

The present results indicated a trend toward improved memory after 6 years of age where 6-year-olds showed the poorest performance on all tasks, indicating that memory systems are still under development at this age. However, memory is divided into multiple systems, and each system develops separately. With regard to semantic memory, an improvement with age was observed, showing gradual maturation. Finally, working memory is characterized by late maturation. Thus, the present data provide an overview of the various memory systems with some nuances that can be observed throughout development.

\section{Conclusions}

Memory plays a primary role in learning. Memory involves interrelated biological, cognitive, sociocultural, and psychological factors that should be considered during human development. The present results showed that the performance of 6-year-olds was lower than all of the other age groups studied. The age factor was shown to be an important variable in several of the tests, demonstrating that memory systems improve throughout childhood. These results may provide a better understanding of what occurs in cases of learning disabilities, injuries, and neuropsychiatric disorders. Further studies are needed on the development of

Table 5. Tests results

\begin{tabular}{|c|c|c|c|c|c|}
\hline \multirow{2}{*}{ Measures } & \multicolumn{5}{|c|}{ Ages (years) } \\
\hline & 6 & 7 & 8 & 9 & 10 \\
\hline$n$ & 16 & 18 & 20 & 16 & 20 \\
\hline \multicolumn{6}{|l|}{ Episodic memory } \\
\hline A6 RAVLT & $5.9(2.4)$ & $7.6(1.8)$ & $8.1(1.7)$ & $8.2(1.9)$ & $9.1(1.7)$ \\
\hline RecA RAVLT & $10.4(1.8)$ & $11.1(1.1)$ & $11.5(0.8)$ & $10.6(1.8)$ & $11.5(0.9)$ \\
\hline Rey figure recall & $11.3(9.0)$ & $10.1(6.5)$ & $12.6(4.6)$ & $15.9(5.8)$ & $22.0(6.2)$ \\
\hline \multicolumn{6}{|c|}{ Semantic memory } \\
\hline VF semantic & $26.4(6.8)$ & $33.6(9.9)$ & $34.8(8.4)$ & $43.9(11.3)$ & $42.2(7.3)$ \\
\hline Inf WISC & $8.2(2.6)$ & $11.4(3.5)$ & $14.1(4.0)$ & $17.1(3.4)$ & $19.4(3.5)$ \\
\hline Vocab WISC & $19.9(3.4)$ & $21.6(5.6)$ & $26.4(5.5)$ & $30.1(6.3)$ & $31.0(3.9)$ \\
\hline \multicolumn{6}{|l|}{ Working memory } \\
\hline A1 RAVLT & $4.9(1.5)$ & $5.3(1.7)$ & $6.0(1.3)$ & $6.0(1.2)$ & $6.7(1.6)$ \\
\hline Dig WISC & $9.3(1.9)$ & $10.0(1.8)$ & $11.4(3.0)$ & $12.6(3.3)$ & $12.4(2.6)$ \\
\hline Rey figure copy & $19.3(9.6)$ & $27.6(6.8)$ & $27.3(6.5)$ & $31.0(5.5)$ & $34.1(2.6)$ \\
\hline
\end{tabular}


memory and other cognitive functions in school-age children at other socioeconomic levels. Similarly, a larger sample will help generate data and a more indepth understanding of what changes occur in memory throughout the school years.

\section{Acknowledgments}

This work was supported by FAPERJ, CNPq and CAPES. The authors would like to thank Gabriela Touche for valuable help, the great support of Prof. Denise Morsch and for all the families and schools that participated and assisted us in this project.

\section{References}

Alloway, T. P., Gathercole, S. E., \& Pickering, S. J. (2006). Verbal and visuospatial short-term and working memory in children: Are they separable? Child Development, 77(6), 1698-1716.

American Psychiatric Association (1994). Diagnostic and statistical manual of mental disorders, 4th edition. Washigton, D.C.: American Psychiatric Press.

Anderson, V. (2001). Assessing executive functions in children: Biological, psychological, and developmental considerations. Pediatric Rehabilitation, 4(3), 119-136.

Anderson, P., Anderson, V., \& Garth, J. (2001). Assessment and development of organizational ability: The Rey Complex Figure Organizational Strategy Score (RCF-OSS). Clinical Neuropsychologist, 15(1), 81-94.

Anderson, V. A., \& Lajoie, G. (1996). Development of memory and learning skills in school-aged children: a neuropsychological perspective. Applied Neuropsychology, 3(3-4), 128-139.

Baddeley, A. (2009). Working memory. In A. D. Baddeley, M. W. Eysenck, \& M. C. Anderson (Eds.), Memory (pp. 41-68). New York: Psychology Press.

Baddeley, A. D. (2002). Is working memory still working? European Psychologist, 7(2), 85-97.

Barkley, R. A. (2001). The executive functions and self-regulation: An evolutionary neuropsychological perspective. Neuropsychology Review, 11(1), 1-29.

Barr, R., Dowden, A., \& Hayne, H. (1996). Developmental changes in deferred imitation by 6- to 24-month-old infants. Infant Behavior and Development, 19(2), 159-170.

Bauer, P. J. (2006). Constructing a past in infancy: a neurodevelopmental account. Trends in Cognitive Sciences, 10(4), 175 181.

Beck, A., Ward, C. H., Mendelsom, M., Mock J., \& Erbaugh, J. (1961). An inventory for measuring depression. Archives of General Psychiatry, 4, 561-571.

Brocki, K. C., \& Bohlin, G. (2004). Executive functions in children aged 6 to 13: A dimensional and developmental study. Developmental Neuropsychology, 26(2), 571-593.

Capovilla, A. G. S., Gütschow, C. R. D., \& Capovilla, F. C. (2004). Habilidades cognitivas que predizem competência de leitura e escrita. Psicologia: Teoria e Prática, 6(2), 13-26.

Carneiro, M. P. (2007). Desenvolvimento da memória na criança: O que muda com a idade? Psicologia: Reflexão e Crítica, 21(1), 51-59.

Carver, L. J., Bauer, P. J., \& Nelson, C. A. (2000). Associations between infant brain activity and recall memory. Developmental Science, 3(2), 234-246.

Ceci, S. J., \& Howe, M. J. A. (1978). Age-related differences in free recall as a function of retrieval flexibility. Journal of Experimental Child Psychology, 26(3), 432-442.

Clark, C. R., Paul, R. H., Williams, L. M., Arns, M., Fallahpour, K., Handmer, C., \& Gordon, E. (2006). Standardized assessment of cognitive functioning during development and aging using an automated touchscreen battery. Archives of Clinical Neuropsychology, 21(5), 449-467.

Conlin, J. A., Gathercole, S. E., \& Adams, J. W. (2005). Children's working memory: Investigating performance limitations in complex span tasks. Journal of Experimental Child Psychology, 90(4), 303-317.

Cowan, N. (1988). Evolving conceptions of memory storage, selective attention, and their mutual constraints within the human information-processing system. Psychological Bulletin, 104(2), 163-191.

Dempster, F. N., \& Rohwer, W. D., Jr. (1983). Age differences and modality effects in immediate and final free recall. Child Development, 54(1), 30-41.

Diniz, L. F. M., Cruz, M. F., Torres, V. M., \& Cosenza, R. M. (2000). O teste de aprendizagem auditivo-verbal de Rey: Normas para uma população brasileira. Revista Brasileira de Neurologia, 36(3), 79-83.

Farrar, M. J., \& Goodman, S. (1992). Developmental changes in event memory. Child Development, 63(1), 173-187.

Fernando, K., Chard, L., Butcher, M., \& McKay, C. (2003) Standardization of the Rey Complex Figure Test in New Zealand children and adolescents. New Zealand Journal of Psychology, 32(1), 33-38.

Fivush, R. (2011). The development of autobiographical memory. Annual Review of Psychology, 62, 559-582.

Flores-Mendoza, C. E., Mansur-Alves, M., Lelé, A. J., \& Bandeira, D. R. (2007). Inexistência de diferenças de sexo no fator $g$ (inteligência geral) e nas habilidades específicas em crianças de duas capitais Brasileiras. Psicologia: Reflexão e Crítica, 20(3), 499-506.

Frisk, V., Jakobson, L. S., Knight, R. M., \& Robertson, B. (2005). Copy and recall performance of 6-8-year-old children after standard vs. step-by-step administration of the Rey-Osterrieth complex figure. Child Neuropsychology, 11(2), 135-152.

Gathercole, S. E. (1998). The development of memory. Journal of Child Psychology and Psychiatry, and Allied Disciplines, 39(1), 3-27.

Gindri, G., Keske-Soares, M., \& Mota, H. B. (2007). Working memory, phonological awareness and spelling hypothesis (original title: Memória de trabalho, consciência fonológica e hipótese de escrita). Pró-Fono Revista de Atualização Científica, 19(3), 313-322.

Greenbaum, J. L., \& Graf, P. (1989). Preschool period development of implicit and explicit remembering. Bulletin of the Psychonomic Society, 27(5), 417-420.

Grivol, M. A., \& Hage, S. R. V. (2010). Phonological working memory: A comparative study between different age groups. Jornal da Sociedade Brasileira de Fonoaudiologia, 23(3), 245-251.

Instituto Brasileiro de Geografia e Estatística (IBGE) (1999). Pesquisa Nacional por amostra de domicílios (PNAD). Rio de Janeiro.

Kail, R., \& Nippold, M. A. (1984). Unconstrained retrieval from semantic memory. Child Development, 55(3), 944-951.

Klenberg, L., Korkman, M., \& Lahti-Nuuttila, P. (2001). Differential development of attention and executive functions in 3- to 12-yearold Finnish children. Developmental Neuropsychology, 20(1), $407-$ 428.

Kovacs, M. (1983). The children's depression inventory: A selfrated depression scale for school-aged youngsters [unpublished manuscript]. Pittsburgh: University of Pittsburgh.

Kovacs, M. (1992). Children's depression inventory. North Tonawanda, N.Y.: Multi-Health System.

Kramer, J. H., Delis, D. C., Kaplan, E., O’Donnell, L., \& Prifitera, A. (1997). Developmental sex differences in verbal learning. Neuropsychology, 11(4), 577-584.

Levin, H. S., \& Hanten, G. (2005). Executive functions after traumatic brain injury in children. Pediatric Neurology, 33(2), 79-93.

Lowe, P. A., Mayfield, J. W., \& Reynolds, C. R. (2003). Gender differences in memory test performance among children and adolescents. Archives of Clinical Neuropsychology, 18(8), 865-878.

Mandler, J. M., \& McDonough, L. (1995). Long-term recall of event sequences in infancy. Journal of Experimental Child Psychology, 59(3), 457-474.

March, J. S., Parker J. D., Sullivan, K. Stallings P., \& Conners C. K. (1997) The Multidimensional Anxiety Scale for Children (MASC): factor structure, reliability, and validity. Journal of the American Academy of Child and Adolescent Psychiatry, 36(4), 554-565.

McGivern, R. F., Huston, J. P., Byrd, D., King, T., Siegle, G. J., \& Reilly, J. (1997). Sex differences in visual recognition memory: support for a sex-related difference in attention in adults and children. Brain and Cognition, 34(3), 323-336.

Muñoz-Céspedes, J. M., \& Tirapu-Ustárroz, J. (2004). Rehabilitación de las funciones ejecutivas. Revista de Neurología, 38(7), 656-663.

Nelson, K., \& Fivush, R. (2004). The emergence of autobiographical memory: A social cultural developmental theory. Psychological Review, 111(2), 486-511.

Nieto, A., Galtier, I., Barroso, J., \& Espinosa, G. (2008). Fluencia verbal en niños españoles en edad escolar: Estudio normativo piloto y análisis de las estrategias organizativas. Revista de Neurología, 46(1), 2-6. 
Oliveira, M., Rigoni, M., Andretta, I., \& Moraes, J. F. (2004). Validação do Teste Figuras Complexas de Rey na população Brasileira. Avaliação Psicológica, 3(1), 33-38.

Oliveira, R. M., \& Charchat-Fichman, H. (2008). Brazilian children performance on Rey's Auditory Verbal Learning Paradigm. Arquivos de Neuropsiquiatria, 66(1), 40-44.

Pagliuso, L., \& Pasian, S. R. (2007). As Figuras Complexas de Rey: Normas preliminares com crianças de 9 e 10 anos. PSICO, 38(2), 148-156.

Rey, A. (1998/1999). Teste de cópia e de reprodução de memória de figuras geométricas complexas: Manual/André Rey: revisão técnica Teresinha Rey, Lucia Fleury Franco; tradução Teresinha Rey, Lucia Cristina Fleury Franco. São Paulo: Casa do Psicólogo.

Sauzéon, H., Lestage, P., Raboutet, C., N'Kaoua, B., \& Claverie, B. (2004). Verbal fluency output in children aged 7-16 as a function of the production criterion: qualitative analysis of clustering, switching processes, and semantic network exploitation. Brain and Language, 89(1), 192-202.

Simões, M. R. (2002). Utilizações da WISC-III na avaliação neuropsicológica de crianças e adolescentes. Paidéia, 12(23), 113-132.

Souza, A. R. M., \& Sisto, F. F. (2001). Dificuldade de aprendizagem em escrita, memória e contradições. Psicologia Escolar e Educacional, 5(2), 39-47.

Squire, L. R. (2009). Memory and brain systems: 1969-2009. Journal of Neuroscience, 29(41), 12711-12716.

Stein, L. M. (1994). TDE: Teste de Desempenho Escolar: Manual para aplicação e interpretação. São Paulo: Casa do Psicólogo.
Strauss, E., Sherman, E. M. S., \& Spreen, O. (2006). A compendium of neuropsychological tests: Administration, norms, and commentary. New York: Oxford University Press.

Thilers, P. P., MacDonald, S. W. S., \& Herlitz. A. (2007). Sex differences in cognition: The role of handedness. Physiology and Behavior, 92(1-2), 105-109.

Vakil, E., Blachstein, H., \& Sheinman, M. (1998). Rey AVLT: Developmental norms for children and the sensitivity of different memory measures to age. Child Neuropsychology, 4(3), 161-177.

Vakil, E., Greenstein, Y., \& Blachstein, H. (2010). Normative data for composite scores for children and adults derived from the Rey Auditory Verbal Learning Test. Clinical Neuropsychologist, 24(4), 662-677.

Vaz, I. A., Cordeiro, P. M., Macedo, E. C., \& Lukasova, K. (2010). Working memory in children assessed by the Brown-Peterson Task (original title: Memória de trabalho em crianças avaliada pela Tarefa de Brown-Peterson). Pró-Fono Revista de Atualização Cientifica, 22(2), 95-100.

Wechsler, D. (2006). WISC-III: Apostila de instruções para aplicação e avaliação do teste: Escala de inteligência Wechsler para crianças/ David Wechsler adaptação e padronização de uma amostra brasileira — primeira edição Vera Lúcia Marques de Figueiredo. ( $3^{\mathrm{a}}$ ed.). São Paulo: Casa do Psicólogo.

Weller, E. B., Weller, R. A., Rooney, M. T., \& Fristad, M. A. (1999). Children's interview for psychiatric syndromes: Parent version. Washington, D.C.: American Psychiatric Press. 
